\title{
Heterologous Expression and Functional Characterization of CAP18 from Oryctolagus cuniculus
}

\author{
Mahla Nikpoor ${ }^{1}$, Azadeh Lohrasbi-Nejad*1, Jafar Zolala ${ }^{1}$
}

\begin{abstract}
Background: Antimicrobial peptides belong to the innate defence system of creatures. These peptides attach to the bacterial membrane in order to die microorganisms by penetrating them. Hence, biotechnology researchers pay more attention to produce antimicrobial peptides for use in various fields. The studies showed that rabbit tissue with inflammation and skin ulcers would be producing CAP18 peptide, which belongs to the cathelicidin group.

Methods: In this study, the optimized sequence of the cap18 gene was placed into the pPICZA $\alpha$ plasmid after the alpha-factor signal and transformed into Pichia pastoris (X-33 strain). Purification of the recombinant peptide was done based on its histidine tail at C-terminal, and western blotting method was used to demonstrate the purification of rCAP18. The antibacterial activity of the purified and desalted rCAP18 was investigated at different concentrations against pathogenic bacteria.

Results: The maximum expression level of rCAP18 (17.5 kDa) was seen $90 \mathrm{~h}$ after induction of alcohol oxidase I (AOX1) promoter with methanol. The concentration of rCAP18 was $33 \mathrm{mg} / \mathrm{L}$ after purification with Ni-NTA Sepharose column. The function of $\mathrm{rCAP} 18(4.3,5.7,7 \mu \mathrm{g} / \mathrm{ml})$ was investigated against Escherichia coli, Pseudomonas aeruginosa, and Staphylococcus aureus. Results showed that $\% \mathrm{CFU} / \mathrm{cm}^{2}$ reached $28 \%$ after $P$. aeruginosa cells treatment with $7 \mu \mathrm{g} / \mathrm{ml}$ of rCAP18.

Conclusions: This study presented the findings related to heterologous expression of capl8 gene, and evaluation of rCAP18 antibacterial effects. Our results showed that rCAP18 plays a significant role in inhibiting bacterial growth, especially Gram-negative bacteria.
\end{abstract}

Keywords: Antibacterial activity, Cathelicidin, Recombinant CAP18, Heterologous expression.

\section{Introduction}

Antimicrobial peptides (AMPs) are the most critical host defense molecules in the innate immune system. So far, more than 5,000 various types of these peptides have been synthesized or discovered (1). AMPs are an amphipathic molecule which contains from 5 to more than 100 amino acids. They include hydrophobic and cationic residues (2) and show a broad range of antimicrobial activity $(3,4)$. Furthermore, AMPs can interact with the pathogens' surface and destroy them due to their amphipathic nature and positive residues. These interactions between AMPs and the hydrophobic areas of the membrane led to the formation of channels or pores to bacterial death $(5,6)$. Therefore, bacteria have low resistance relative to AMPs (7). One of the reasons which are interested in researchers about antimicrobial peptides is the bacterial resistance to conventional antibiotics. Antibiotics play an essential role in modern therapeutic systems and act as adjuncts to the innate immune system. However, the advent of antibiotic-resistant strains led to a continuous search for finding different kinds of compounds with high efficiency (8-10). Since 
AMPs' goal is prokaryotic cell membranes, they are classified into the antibiotic group to reduce bacterial resistance risk (11). Some of these peptides are present on epithelial tissue surfaces in mammals and act as barriers to preventing microbial invasion (12). The most critical peptides in mammalian skin are Betadefensin and cathelicidin induced by skin ulcers or inflammation. One gene has been known for the cathelicidin group in rodents and humans, while pigs, horses, and cows have several genes (12). hCAP18/LL37 is the only member of the human cathelicidin group expressed in neutrophils, skin epithelial cells, the gastrointestinal tract, and the genital tract (13). There are 37 amino acids from the C-terminal of hCAP18 that released and made LL37 peptide, which has high ability than its precursor into antibacterial activity (14).

Several of these peptides have been produced based on recombinant DNA technology due to their importance in the medical and pharmacy fields. Clinical use of antibacterial peptides for the treatment of several types of pathogenic infections has been investigated. Jacobsen et al. (15) used hCAP18/LL-37 to treat burn wound infections in 2005, and Kougias et al. (16) showed the positive effect of alpha-defensin in preventing vascular diseases. Cathelicidin peptides have unique properties that make them useful as desirable pharmaceutical agents (17-19). Cathelicidins have an immediate effect on bacteria growth inhibition; meanwhile, they quickly create bacteria's morphological changes. These changes are mostly related to the permeability of peptides in the bacterial membrane (18). In a study, the activity of five different cathelicidin types; human (hCAP18), sheep (SMAP29, SMAP34), rabbit (CAP18), rat (rCAMP), and mice (mCAMP) against microorganisms was examined by Travis and his colleagues. Their findings showed that the rabbit CAP18 had the highest antibacterial activity than the other peptides (20). CAP18 relating to rabbit (Oryctolagus cuniculus) is a cationic antimicrobial peptide containing 171 amino acids (29 and 142 amino acids belonging to signal and the main chain of the peptide, respectively) with $18 \mathrm{kDa}$ molecular weight. CAP18 is a thermostable peptide without cytotoxic and hemolytic effects (21). It is expressed in neutrophil cells, bound to lipopolysaccharide (LPs), and targets microorganisms' membranes (19). Therefore, it can inhibit the growth of microorganisms, especially Gram-negative bacteria.

In this study, subcloning and expression of the rabbit cap 18 gene were investigated. Due to two disulfide bonds in the $\mathrm{N}$-terminal region of the peptide, Pichia Pastoris considered a host. Our results showed that the expression and purification of rCAP18 were performed successfully, and this recombinant peptide had an antibacterial activity for Gram-positive and Gram-negative bacteria.

\section{Materials and Methods \\ Microorganisms and reagents}

Pichia pastoris (strain X-33), and E. coli (strain DH5 $\alpha$ ) were prepared from Tarbiyat Modares University (Tehran, Iran). The pPICZA $\alpha$ plasmid was obtained from our laboratory and used as the cloning vector. Bacterial reference strains such as $P$. aeruginosa, S. aureus, and Klebsiella pneumonia were obtained from the Iranian Research Organization for Science and Technology (Tehran, Iran). All enzymes, including restriction enzymes, T4 DNA ligase, and alkaline phosphatase, were bought from Thermo Fisher Scientific Co., Ltd. (China). DNA gel extraction and plasmid extraction kits purchased from Bioneer Inc., (China). Tricine, Zeocin antibiotic purchased from Sigma-Aldrich Chimie (France). Ni-NTA Sepharose prepared from Invitrogen Inc., (Canada). Silver nitrate, yeast extract, tryptone, agar, other chemical salts, and gel electrophoresis materials took from Merck Millipore Company (China).

\section{Codon optimization and designing the construction of cap18 gene}

We have used the coding sequence of the cap18 gene with the M73998.1 accession number. This gene contains 516 bp of the nucleotide that $87 \mathrm{bp}$ of them are translated to 
a secretory signal cleaved after expression. Moreover, $426 \mathrm{bp}$ of this gene encodes the main structure of the CAP18 peptide. pPICZA $\alpha$ vector with a secretory signal (alpha-factor signal) was considered for the secretory expression of the CAP18. As a result, we ignored the native secretory signal sequence of the capl8 gene for the gene's desired sequence to be placed after the alphafactor signal. Codon optimization of the cap18 gene was done based on the $P$. pastoris codon usage. At the 5' end of the gene, the Xhol cleavage site was added and then followed by kex2 and ste 13 cleavage sites. At the 3' end of the gene, a sequence relevant to histidine (6 residues) placed before the stop codon, and lastly, the Not1 cleavage site was added (Fig. 1). The final sequence of the cap18 gene was synthesized by Bio Basic Inc., (Ontario, Canada) and inserted into the pPUC57 vector.

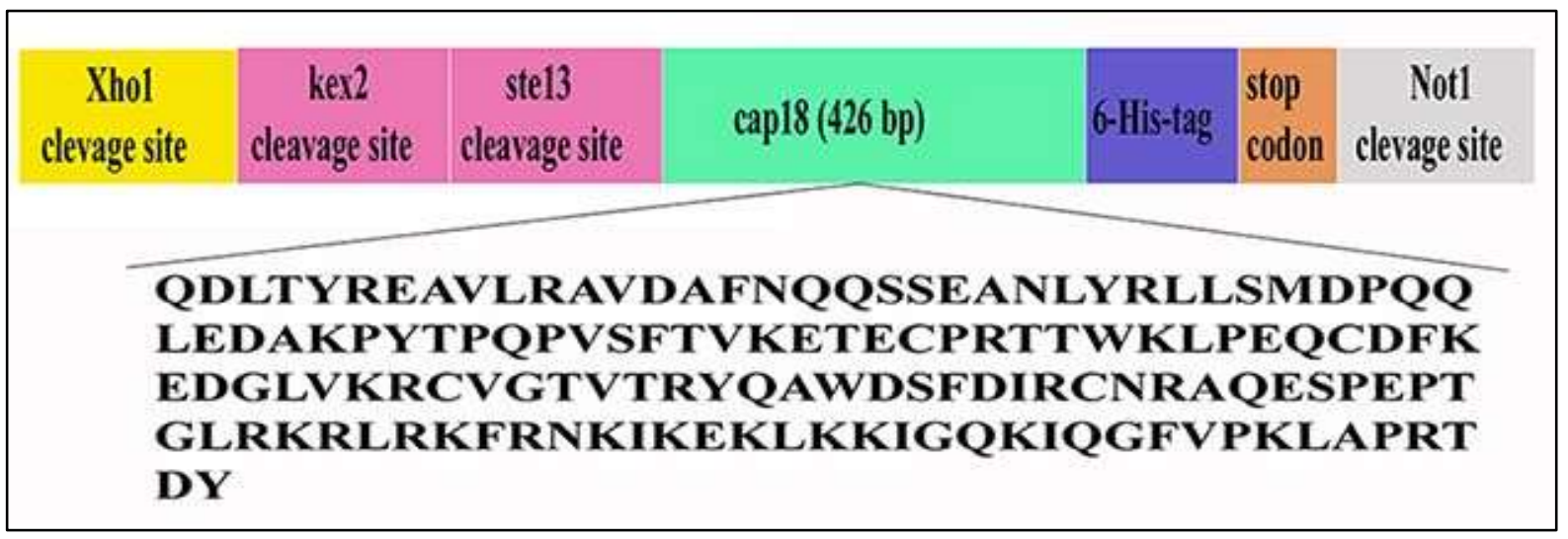

Fig. 1. Schematic gene construction of cap18 for insertion in pPICZA $\alpha$ expression vector, an amino acid sequence related to the main structure of CAP18 peptide shown at the bottom of the figure.

\section{Production of recombinant vector pPICZAa-cap18}

At first, pPUC57 plasmid contains synthesized capl8 gene transferred into DH5 $\alpha$ competent cells and extracted from bacteria via the Bioneer plasmid extraction kit. cap 18 gene detached from pPUC57 plasmid through a double digestion reaction with Xhol and Not1 endonucleases. Analysing the product was done by $1 \%$ agarose gel electrophoresis (SUB$10 \times 7$ model, Paya Pajoohesh, Tehran, Iran). The same restriction enzymes then linearized pPICZA $\alpha$ plasmid at $37{ }^{\circ} \mathrm{C}$. Dephosphorylating of pPICZA $\alpha$ vector was performed by $1 \mu$ l alkaline phosphatase at 37 ${ }^{\circ} \mathrm{C}, 15 \mathrm{~min}$. All of the experiment's enzymes were removed from the solution by the DNA precipitation method with ethanol. Prepared plasmid (75 ng) and purified capl 18 gene (225 ng) were ligated by adding T4 DNA ligase (22 ${ }^{\circ} \mathrm{C}$ for $2 \mathrm{~h}$ and finally $14 \mathrm{~h}$ at $4{ }^{\circ} \mathrm{C}$ ). Recombinant plasmid (pPICZA $\alpha$-cap18) was transferred to the susceptible DH5 $\alpha$ host cells, and then bacterial cells were cultured on the plate which contains Zeocin antibiotic. To confirm the cloning steps, a single colony was cultured in $5 \mathrm{ml} \mathrm{LB}$ broth, including Zeocin antibiotic $(25 \mu \mathrm{l} / \mathrm{ml}$ final concentrations). The plasmid was then extracted according to the Bioneer kit protocol. Single and double digestion tests were performed on the recombinant vector by restriction enzymes. Products were assessed by gel electrophoresis. Finally, the inserted gene sequencing was done by Macrogen, Inc., (Seoul, South Korea) and analysed by Chromas software (v.2.6.6, Technelysium Pty Ltd, South Brisbane, Australia; 1996).

Transferring the recombinant pPICZA $\alpha-$ cap18 vector into $P$. pastoris

The recombinant vector (pPICZA $\alpha$-cap18) was linearized by the $S a c l$ restriction enzyme $\left(37{ }^{\circ} \mathrm{C}, 2 \mathrm{~h}\right)$, then the enzyme was excluded from the solution by DNA precipitation with ethanol. X-33 competent cells were prepared according to the previous protocol (22). The pPICZA $\alpha$-cap18 vector (2000 ng) was transferred into the $\mathrm{X}-33$ competent cells using 
the electroporation system (Gene Pulser Xcell Electroporation System, BIO-RAD Laboratories, Inc., Philadelphia, USA). After adding $1 \mathrm{ml}$ of cold sorbitol (1 M), the sample was transferred into a $15 \mathrm{ml}$ Falcon and incubated at $30{ }^{\circ} \mathrm{C}$ for $2.5 \mathrm{~h}$. Finally, the cells were transferred to a solid YPDS medium containing $100 \mu \mathrm{g} / \mathrm{ml}$ Zeocin antibiotics. Plates were incubated at $28{ }^{\circ} \mathrm{C}$ until recombinant cell growth.

\section{Expression and purification of rCAP18 protein}

To investigate the expression of the rCAP18, one of the colonies that had grown on the solid plate includes antibiotics cultured in the $5 \mathrm{ml}$ YPG medium overnight $\left(30^{\circ} \mathrm{C}, 150 \mathrm{rpm}\right)$. The cells precipitated using Eppendorf multipurpose microcentrifuges 5430R (Eppendorf AG, Hamburg, Germany) at 8000 $\mathrm{g}$ for $10 \mathrm{~min}$. The cellular deposition was then transferred to a fresh YPM medium, while the $\mathrm{OD}_{600}$ of the new medium reached 1. The expression of rCAP18 was induced by adding $0.5 \%(V / V)$ methanol every $24 \mathrm{~h}$, then $1 \mathrm{ml}$ of culture medium collected at a specific time after induction $(6,18,30,42,48,54,66,78$, 90 , and $96 \mathrm{~h}$ ). The cells were precipitated by centrifuge at $11000 \mathrm{~g}$, and their supernatant was stored at $-70{ }^{\circ} \mathrm{C}$. Due to evaluate the intracellular expression of rCAP18, we lysed the collected X-33 cells by ceramic beads based on the previous protocol (22). Cell debris was removed from protein solution by centrifuge at $11000 \mathrm{~g}$ (15 min). All samples were diluted to $1: 3$ and then investigated by $16 \%$ tris-tricine SDS-PAGE (Mini-PROTEIN II Electrophoresis Cell, BIO-RAD Laboratories, Inc., Philadelphia, USA). Based on the presence of His-tag in the C-terminal of rCAP18, the Ni-NTA Sepharose column was used to purify the recombinant protein. At first, the column was equilibrated by a buffer containing $0.13 \mathrm{mM} \mathrm{NaH} 2 \mathrm{PO}_{4}$ and $1.25 \mathrm{mM}$ $\mathrm{NaCl}$ at $\mathrm{pH}=8$. Then $10 \mathrm{ml}$ of supernatant collected (90 h after methanol induction) slowly passed through the column. When the protein solution completely crossed through the column, resins were soaked by washing buffer containing $0.13 \mathrm{mM} \mathrm{NaH} \mathrm{PO}_{4}, 0.013$
$\mathrm{mM} \mathrm{Na} 2 \mathrm{HPO}_{4}$, and $1.25 \mathrm{mM} \mathrm{NaCl} 0.02 \mathrm{mM}$ imidazole. The recombinant peptides are bound to the column through their polyhistidine tail. Finally, rCAP18 is released from the column by elution buffer $(0.11 \mathrm{mM}$ $\mathrm{NaH}_{2} \mathrm{PO}_{4}, 0.16 \mathrm{mM} \mathrm{NaH}_{2} \mathrm{PO}_{4}, 1.15 \mathrm{mM} \mathrm{NaCl}$, and $0.25 \mathrm{mM}$ imidazole at $\mathrm{pH}=8$ ). Collected samples were assessed by $16 \%$ tris-tricine SDS-PAGE. Then we examined the concentration of purified rCAP18 based on the Bradford protocol.

\section{Western blotting analysis}

Western blot was used to assess rCAP18 expression. Purified rCAP18 loaded on $16 \%$ tris-tricine SDS-PAGE, then electroblotting was done by semi-dry blotting set (Mini TransBlot ${ }^{\circledR}$ Cell, BIO-RAD Laboratories, Inc., Philadelphia, USA) with a constant current $(300 \mathrm{~mA})$ at $4{ }^{\circ} \mathrm{C}$. The nitrocellulose membrane (Sigma-Aldrich Chimie, France) was blocked in a buffer containing $150 \mathrm{mM}$ $\mathrm{NaCl}, 20 \mathrm{mM}$ Tris-base (pH 7.4), and 5\% (W/V) skimmed milk. The blocked membrane was then subjected to the HRP enzyme conjugated anti-polyhistidine antibody for $1 \mathrm{~h}$. After washing it three times during $1 \mathrm{~h}$, the antibodies bounded to proteins were detected by ECL western blotting detection reagent until specific protein bands, including His-tag, were appeared.

\section{Antibacterial activity of rCAP18}

Purified rCAP18 was desalted based on the previous protocol (22). Then the antibacterial activity of recombinant peptide was estimated against pathogenic bacteria such as $E$. coli (ATCC 11229), P. aeruginosa (ATCC 9027), $S$. aureus (ATCC 29213), and K. pneumonia (ATCC 10031). Bacterial cells were grown in TSB medium overnight then diluted to 0.5 Mcfarland densities $\left(1.5 \times 10^{8} \mathrm{CFU} / \mathrm{ml}\right)$. Based on the agar well diffusion method, bacteria plated on the solid plates' surface (containing TSB with agar). Wells at the centre of the plate filled with $50 \mu \mathrm{l}$ rCAP18 protein solution. After $14 \mathrm{~h}$ of incubating plates at $37{ }^{\circ} \mathrm{C}$, the halo's existence on the plates were reviewed. The antibacterial effects of the rCAP18 were 
also analysed using the pour-plate method. Different concentrations of rCAP18 (4.3, 5.3, $7 \mu \mathrm{g} / \mathrm{ml}$ ) were prepared in PBS buffer. After mixing the protein solution with the bacterial cells $\left(5 \times 10^{4}\right.$ cell), all of the suspensions were incubated at $37{ }^{\circ} \mathrm{C}$ for different time intervals $(4,6,12 \mathrm{~h})$. And then, $50 \mu \mathrm{l}$ of them were examined based on the pour-plate method. Plates placed at $37{ }^{\circ} \mathrm{C}$ for $24 \mathrm{~h}$ and $\% \mathrm{CFU}$ (colony forming unit) per one $\mathrm{cm}^{2}$ were counted and compared with control samples for each strain.

\section{Results}

Construction of recombinant vector and transferring into $x-33$ cell

At first, the coding adaptation index (CAI) for the rabbit cap 18 gene was assessed to express in the P. pastoris by the Genscript server. The results showed a value of 0.59 that had a significant distance from the acceptable range for CAI, while the numbers between 0.8-1 are ideal for expressing the gene in the target host. After the optimization and modification of the nucleotide codons, this parameter reached 0.85 . Hence, an optimized cap 18 sequence was synthesized and used.

The pPUC57-cap18 plasmid was doubledigested by two endonucleases (Not1 and Xhol). Then $3 \mu \mathrm{l}$ of the product loaded on $1 \%$ agarose gel. As shown in Fig. 2A, A single band at $479 \mathrm{bp}$ on the gel determined that the isolation of the cap18 gene was done correctly. The DNA fragment was extracted and purified from the gel. The correctness of the steps was confirmed by the electrophoresis test. Then pPICZA $\alpha$ vector was digested by Xhol/Not1 restriction enzymes and then analysed by gel electrophoresis. The presence of an approximately $3600 \mathrm{bp}$ band on the gel indicates that the pPICZA $\alpha$ vector has been cleaved accurately at cutting positions. The capl 8 gene's insertion at the sticky ends of the linearized plasmid was done using the T4 DNA ligase.

At last, recombinant vector pPICZA $\alpha-$ cap18 was transferred into DH5 $\alpha$ competent cells and plated on an LB-agar environment containing Zeocin antibiotic. The extracted recombinant plasmid was investigated using an enzymatic cleavage reaction. Comparison of linearized pPICZA $\alpha$ and pPICZA $\alpha$-cap18 on the gel showed a larger size of the recombinant plasmid due to the insertion of the capl8 gene into it (Fig. 2B). Furthermore, double digestion of pPICZA $\alpha$-capl8 demonstrated a 479 bp band relevant to the cap18 gene. DNA sequencing verified the absence of mutation in the cap18 nucleotides and confirmed that it has correctly placed after the plasmid's secretary signal. Lastly, the linearized pPICZA $\alpha$-capl8 was transferred into X-33 competent cells. Recombinant $P$. pastoris cells grew on the plate that contains antibiotics after 4-5 days.

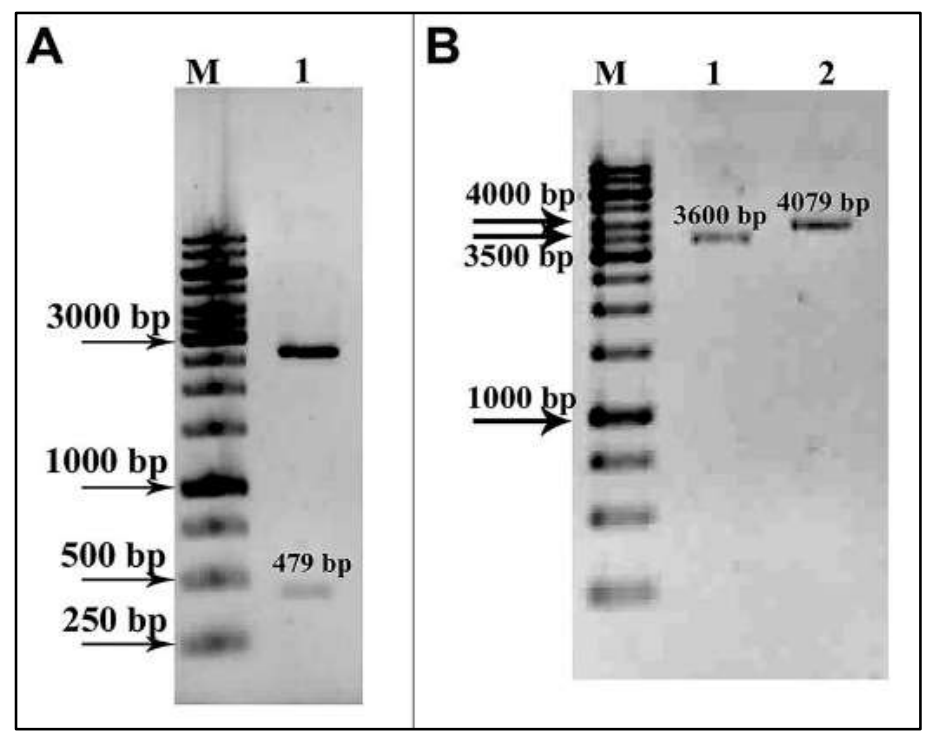

Fig. 2. (A) pPuc57-cap18 plasmid that double-digested with Xhol/Not1. (B) single digested of pPICZA $\alpha$ (lane 1) and pPICZA $\alpha$ cap18 (lane 2) with Xhol restriction enzyme. $\mathrm{M}$ is DNA ladder $1 \mathrm{~Kb}$ and band at the location of 479 bp belongs to cap18 gene. 
Expression, purification and western blotting analysis of rCAP18

A single clone of recombinant $P$. pastoris was grown in $10 \mathrm{ml}$ of YPG medium overnight and conveyed into YPM solution, including $0.5 \%$ (V/V) methanol. One $\mathrm{ml}$ of culture medium was removed at specific time intervals, then supernatants and cells were separated by centrifuge. The secretory and intracellular proteins were analysed using
SDS-PAGE. As indicated in Fig. 3, the band's intensity belonging to the rCAP18 in the supernatant has increased during the time (17.5 kDa position). The maximum expression level of rCAP18 was seen $90 \mathrm{~h}$ after induction by methanol (Fig. 3, lane 8). Evaluating intracellular proteins (Fig. 3, lanes $1,3,5,7)$ referred that the expressed protein was secreted into the medium and had not been collected in the cells.

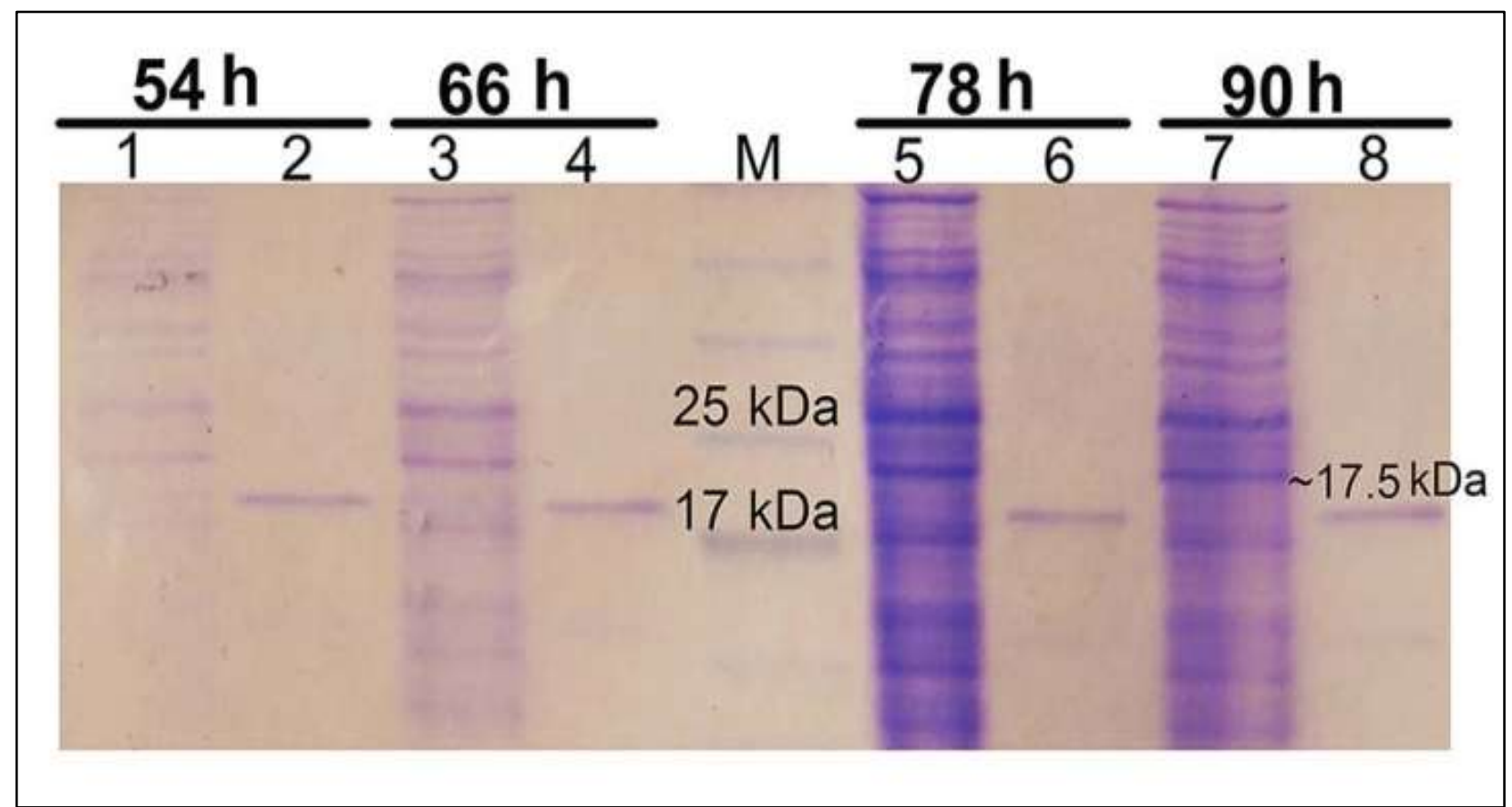

Fig. 3. $16 \%$ tris-tricine SDS-PAGE; the extracellular and intracellular proteins were collected at different time intervals. Lanes 1, 3, 5, and 7 belong to the total intracellular protein, and lanes 2, 4, 6, and 8 belong to the total protein in the supernatant. (M) protein marker. The band at $17.5 \mathrm{kDa}$ location showed the existence of rCAP18.

Since the maximum expression level of rCAP18 happened $90 \mathrm{~h}$ after being induced, the culture medium was collected at this time. The supernatant collected by a centrifuge was used to purify rCAP18 and cross through the column. The output of each step of the $\mathrm{Ni}$ NTA Sepharose column was investigated by $16 \%$ tris-tricine SDS-PAGE. rCAP18 had attached to the column, so it was not found in the solution passed through the column. After washing the resin, non-specific proteins leave the column because of weak interaction with resin. The concentration of non-specific proteins in the prototypes is high and gradually decreases due to more column washing. rCAP18 connected to the column by polyhistidine-tag and then released by adding elution buffer, where a single band at approximately $17.5 \mathrm{kDa}$ position belonged to rCAP18 (Fig. 4A, lanes 1-3). Our results showed that the concentration of rCAP18 was $33 \mathrm{mg} / \mathrm{L}$. We also used the western blot technique to detect individual peptides, including His-tag in eluted samples. The interaction between antibody and recombinant protein occurs as low as $1 \mathrm{ng}$. As indicated in Fig. 4B, a single band was observed in the presence of an anti-His tag antibody for purified samples at the same location with SDS-PAGE. Therefore, we conclude that the purification of rCAP18 was done successfully. 


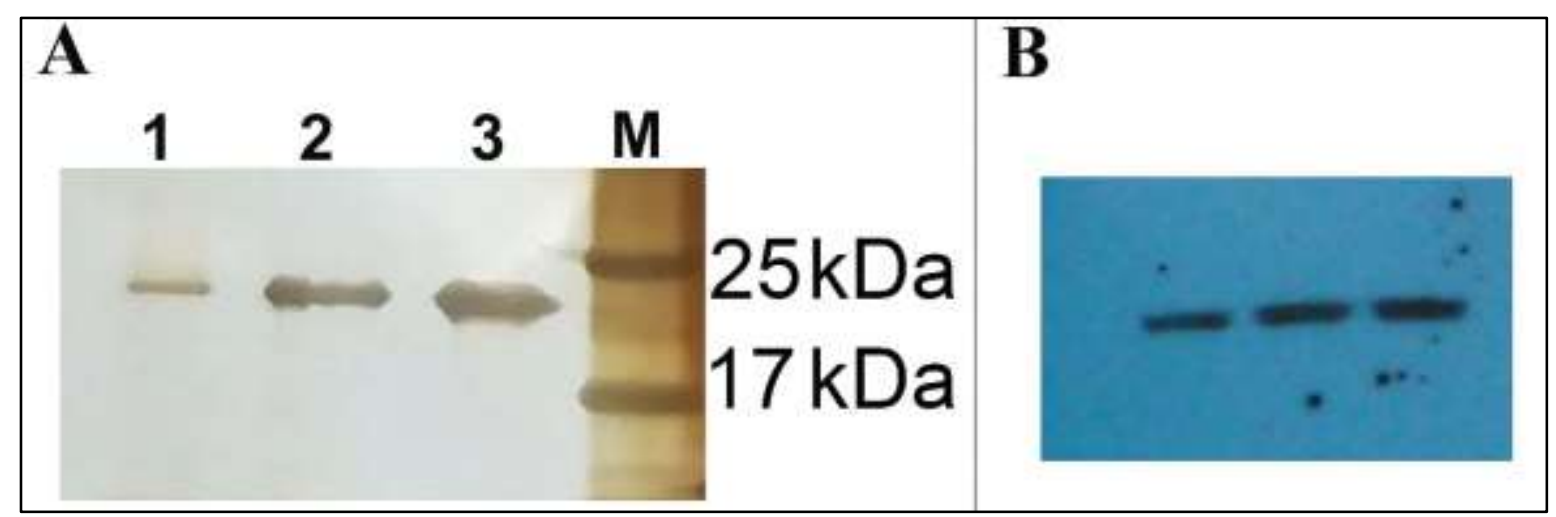

Fig. 4. (A) Silver nitrate stained $16 \%$ tris-tricine SDS-PAGE belonging to purified rCAP18 by the Ni-NTA Sepharose column. Lanes 1 to 3 correspond to eluted samples 1 to $3(17.5 \mathrm{kDa})$. M is protein marker. (B) Western blotting analysis of purified rCAP18 showed bands relevant to the eluted samples.

\section{Antibacterial tests}

Investigation of the effect of rCAP18 on the growth of bacteria through agar well diffusion did not show antibacterial influence. The peptide's diffusion potential in the agar medium has likely decreased based on the size of rCAP18 (17.5 KDa). Our result was consistent with Choyam et al. (23), who published a paper in 2015 and showed that bacteriocin could not diffuse from the well in the agar plate. Thus, the pour-plate method was used for the antibacterial assay. Bacterial cells were treated with various concentrations of rCAP18 in different periods. Meanwhile, samples were cultured based on the pour-plate method, and the number of colonies was counted and compared. As indicated in Fig. $5 \mathrm{~A}, 4.3 \mu \mathrm{g} / \mathrm{ml}$ rCAP18 had little effect on the growth inhibition of $E$. coli. Our results showed that increasing the during incubation time had little effect on inhibiting $E$. coli. There was only $7 \%$ of bacterial cells' growth reduction after $12 \mathrm{~h}$ of peptide incubation with bacteria. The use of peptide at this concentration $(4.3 \mu \mathrm{g} / \mathrm{ml})$ showed the greatest inhibitory effect on bacterial growth against $P$. aeruginosa strain. $\% \mathrm{CFU} / \mathrm{cm}^{2}$ was $86 \%, 76 \%$, and $62 \%$ after 4,6 , and $12 \mathrm{~h}$ of incubation bacteria with rCAP18, respectively. Evaluation of the effect of $4.3 \mu \mathrm{g} / \mathrm{ml} \mathrm{rCAP} 18$ on growth inhibition of $S$. aureus showed a slowly decreasing trend depending on the incubation duration. As the peptide concentration increased to $5.7 \mu \mathrm{M}$, the more antibacterial effect was observed against different strains. As indicated in Fig. 5B, after incubation of $E$. coli with peptide at different time intervals such as 4, 6, and $12 \mathrm{~h}$, $\% \mathrm{CFU} / \mathrm{cm}^{2}$ reached $80 \%, 62 \%$, and $50 \%$, respectively. The most significant inhibitory effect of $5.7 \mu \mathrm{g} / \mathrm{ml}$ rCAP18 was observed on the $P$. aeruginosa strain. Our results determined that $\% \mathrm{CFU} / \mathrm{cm}^{2}$ decreased to $30 \%$ after the 12-hour treatment of bacteria with peptide. The concentration of $7 \mu \mathrm{m}$ rCAP18 has played an inhibitory role for all three bacterial strains (Fig. 5C). In this case, $\% \mathrm{CFU} / \mathrm{cm}^{2}$ was $36 \%, 28 \%$, and $32 \%$ for $E$. coil, $P$. aeruginosa, and $S$. aureus, respectively. According to the results, it seems that rCAP18 has specific activity against Gram-negative bacteria.

Furthermore, in Fig. 5D, we showed the positive effect of peptide concentration on bacterial growth inhibition for the $P$. aeruginosa strain. After $4 \mathrm{~h}$ of treatment of bacterial cells with rCAP18, cells were cultured on the plate. As seen in the upper row of Fig. 5D, the number of single clones appearing on the plate was reduced by increasing the amount of recombinant peptide compared to the untreated sample (column 1). The difference in concentration-dependent growth inhibitor rate is becoming more pronounced with 12-hour treating of bacterial cells with the peptide (Fig. 5D, lower row). 


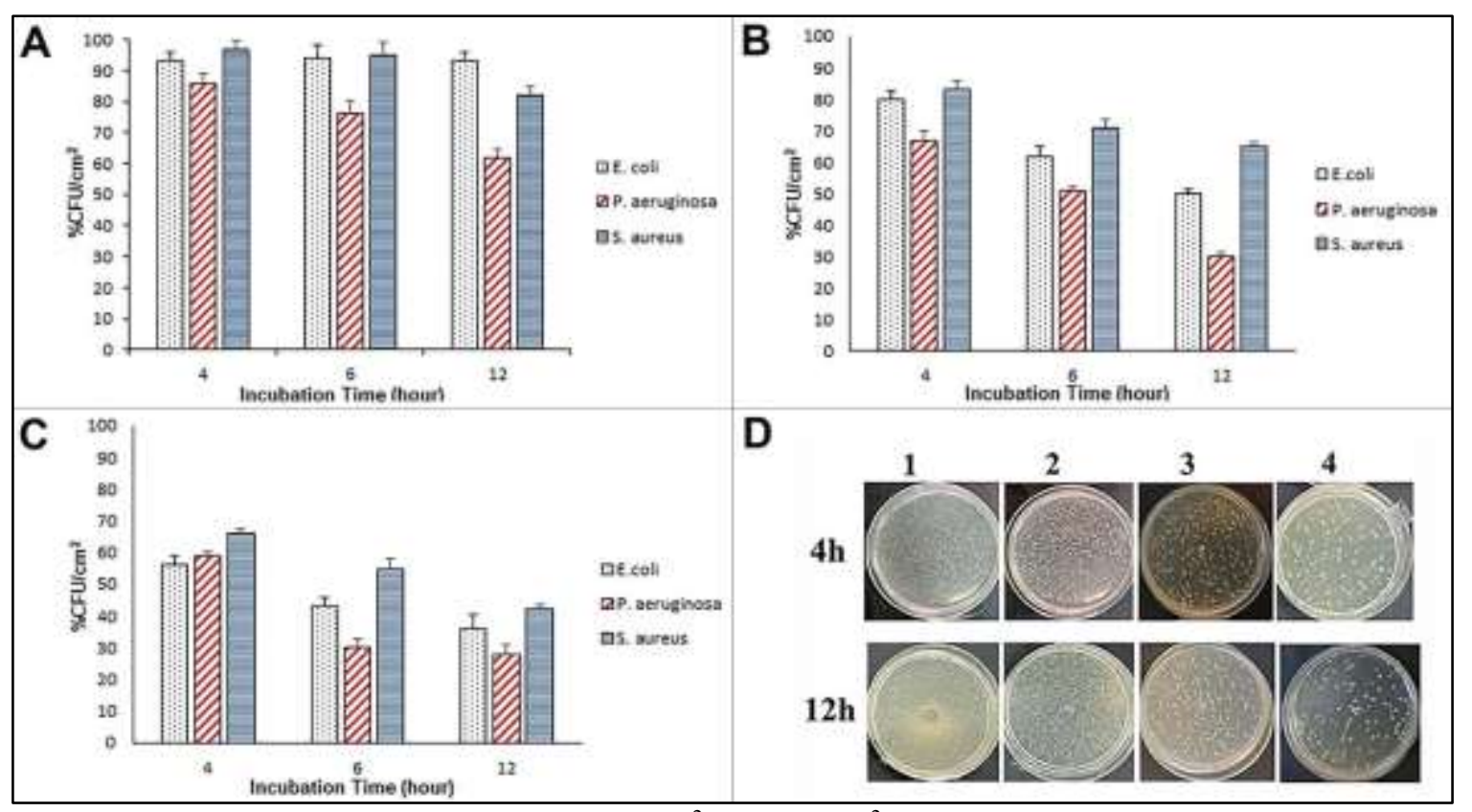

Fig. 5. Percentage of colony forming unit per one $\mathrm{cm}^{2}\left(\% \mathrm{CFU} / \mathrm{cm}^{2}\right)$ of $E$. coli, $P$. aeruginosa, and $S$. aureus after incubation of various concentrations of rCAP18 with $5 \times 10^{4}$ bacterial cells at $4,6,12 \mathrm{~h}$. (A) $4.3 \mu \mathrm{g} / \mathrm{ml},(\mathrm{B}) 5.7 \mu \mathrm{g} / \mathrm{ml},(\mathrm{C})$ $7 \mu \mathrm{g} / \mathrm{ml}$ of rCAP18. (D) Growth level of $P$. aeruginosa treated with various concentrations of rCAP1 at different incubation times; (1) positive control without rCAP18, (2) $4.3 \mu \mathrm{g} / \mathrm{ml}$, (3) $5.7 \mu \mathrm{g} / \mathrm{ml}$, (4) $7 \mu \mathrm{g} / \mathrm{ml}$ of rCAP18 was added to bacterial cells and after specific incubation time cultured on plates. The rows belong to $4 \mathrm{~h}$ and $12 \mathrm{~h}$.

\section{Discussion}

Antimicrobial peptides are some kinds of small molecules that can inhibit the growth of different microorganisms. These peptides are found in most innate defense systems of living organisms, such as bacteria, insects, plants, and animals. Cathelicidins are critical antimicrobial peptides in mammalian that have positive charge residues and hydrophobic regions on their surface. These peptides can bind to the bacterial membrane and disrupt their membrane.

In this study, the heterologous expression of CAP18 was investigated in $P$. pastoris as host cells. The use of an expression vector with the alpha-mating factor was led to the secretion of the peptide into the culture medium and easier purification from other proteins. So far, several antibacterial peptides such as human cathelicidin (hCAP18/LL-37) (24,25), sheep beta-defensin (26), bovine lactoferrampinlactoferricin (27), cecropin D (28), pleurocidin (29), and shrimp Ch-penaeidin (30) have been expressed in P. pastoris. In these studies, an expression vector had been used with alcohol oxidase (AOX) or glyceraldehyde3-phosphate dehydrogenase (pGAP) promoters $(31,32)$. AOX promoter is strongly controlled by methanol induction. Thus, foreign protein generating is accurately controlled, especially when the peptide is toxic to the host. Human CAP18 has been expressed via vectors consist of the pGAP (24) and AOX promoters (25). In our study, the pPICZA $\alpha$ vector was considered for secretory expression of rCAP18 peptide in $P$. pastoris. The recombinant gene was induced by $0.5 \%$ methanol in YPM media. The maximum expression level of rCAP18 was detected after $90 \mathrm{~h}$ of induction. In another study, Kim et al. (25) obtained the highest amount of hCAP18/LL-37 after $72 \mathrm{~h}$ of induction of pPICZA $\alpha$ vector by $2 \%$ methanol in MM medium. We were able to purify the rCAP18 at a concentration of $33 \mathrm{mg} / \mathrm{L}$ that is consistent with Zhao et al.'s results (26) expressed sheep beta-defensin in the $P$. pastoris. They published that recombinant 
peptide concentration after purification with SP-SEPHADEX (C-25) has reached $35 \mathrm{mg} / \mathrm{L}$. In another study, Hong et al. (24) investigated the intracellular expression of LL37 in $P$. pastoris X-33 strain, but they did not describe the expression level of the recombinant peptide. In 2009, Kim et al. (25) performed cloning of the full-length hCAP18/LL-37 gene; they did not present recombinant peptide concentration, but they confirmed the antibacterial activity of the supernatant without purification. Zhao et al. (26) expressed sheep beta-defensin (msBD-1$\mathrm{T})$ in $P$. pastoris and obtained $80 \mathrm{mg} / \mathrm{L}$ recombinant peptides with $85 \%$ purity. Chen et al. (33) studied the expression of human betadefensin in $P$. pastoris and B. subtilis. Their result showed a low expression level of the recombinant peptide, whereas it was only detectable by Western blot. Tang et al. (27) examined the heterologous expression and purification of bovine lactoferrampinlactoferricin. Their results proved $91 \%$ purity among the concentration of $0.2 \mathrm{mg}$.

According to the antibacterial results, we concluded that Gram-negative bacteria are more sensitive to rCAP18. This outcome was consistent with the results of Ebbensgaard et al. (34) and demonstrated that CAP18 had specific activity against Gram-negative bacteria, especially $P$. aeruginosa. In 2009, the

\section{References}

1. Zhao X, Wu H, Lu H, Li G, Huang Q. Lamp: A database linking antimicrobial peptides. PLoS ONE. 2013;8(6):e66557.

2. Jung YJ, Kang KK. Application of Antimicrobial Peptides for Disease Control in Plants. Plant Breed Biotech. 2014;2(1):1-13.

3. Zhang LJ, Gallo RL. Antimicrobial peptides. Curr Biol. 2016;26(1):14-19.

4.Zasloff M. Antimicrobial peptides of multicellular Organisms. Nature. 2002;415:389-395.

5. Gutsmann T, Hagge SO, Larrick JW, Seydel U, Wiese A. Interaction of CAP18-derived peptides with membranes made from endotoxins or phospholipids. Biophys J. 2001;80(6):2935-45.

6. Oren Z, Lerman JC, Gudmundsson GH, Agerberth B, Shai Y. Structure and organization of the human antimicrobial peptide LL-37 in antibacterial activity of the CAP18 synthesized fragment of rabbit, which is equal to 106-142 amino acids from the end of the C-terminal, was investigated and verified by Larrick et al. (35). However, we selected a whole sequence of CAP18 (1-142 amino acids) for production based on recombinant DNA technology. The peptide length can influence its function, whereas increasing the size is encountered with reduced permeability. The large size of the rCAP18 peptide may be played a role in the absence of growth halo formation on the plate. By considering the fact that antibacterial peptides targeted bacterial membranes, it seems that these peptides have a high potential to become a medicinal compound. However, their formulation and conversion into an effective combination to control and treat infectious diseases require extensive research in this field.

\section{Acknowledgements}

This work was funded by the Research and Technology Institute of Plant Production (RTIPP), Shahid Bahonar University of Kerman, Kerman, Iran, under grant number [900/106]. We are also thankful to the office of vice-chancellor for research, and biotechnology department labs, Shahid Bahonar University of Kerman.

phospholipid membranes: relevance to the molecular basis for its non-cell-selective activity. Biochem J. 1999;341(Pt 3):501-13.

7. Hancock RE. Peptide antibiotics. Lancet. 1997;349(9049):418-22.

8. Moosavi SM, Pouresmaeil O, Zandi H, Emadi S, Akhavan F, Torki A, et al. The evaluation of antibiotic resistance and nalB mutants in pseudomonas aeruginosa isolated from burnt patients of Shohada Mehrab Yazd hospital burn ward. Rep Biochem Mol Biol. 2020;9(2):140-146. 9. Kaviani R, Pouladi I, Niakan M, Mirnejad R. Molecular Detection of Adefg Efflux Pump Genes and their Contribution to Antibiotic Resistance in Acinetobacter baumannii Clinical Isolates. Rep Biochem Mol Biol. 2020;8(4):413-418. 
10. Hancock RE, Diamond G. The role of cationic antimicrobial peptides in innate host defences. Trends Microbiol. 2000;8(9):402-410.

11. Lee TH, Hall KN, Aguilar MI. Antimicrobial peptide structure and mechanism of action: a focus on the role of membrane structure. Curr Top Med Chem. 2016;16(1):25-39.

12. Brandenburg LO, Merres J, Albrecht LJ, Varoga D, Pufe T. Antimicrobial peptides: multifunctional drugs for different applications. Polymers. 2012;4(1):539-560.

13. Cowland JB, Johnsen AH, Borregaard N. hCAP-18, a cathelin/pro-bactenecin-like protein of human neutrophil specific granules. FEBS Lett. 1995;368(1):173-76.

14. Sorensen OE, Follin P, Johnsen AH, Calafat J, Tjabringa GS, Hiemstra PS, et al. Human cathelicidin, hCAP-18, is processed to the antimicrobial peptide LL-37 by extracellular cleavage with proteinase 3. Blood. 2001;97(12):3951-59.

15. Jacobsen F, Mittler D, Hirsch T, Gerhards A, Lehnhardt M, Voss B, et al. Transient cutaneous adenoviral gene therapy with human host defense peptide hCAP-18/LL-37 is effective for the treatment of burn wound infections. Gene Ther. 2005; 12:1494-502.

16. Kougias P, Chai H, Lin PH, Yao Q, Lumsden $\mathrm{AB}$, Chen C. Neutrophil antimicrobial peptide alpha-defensin causes endothelial dysfunction in porcine coronary arteries. J Vasc Surg. 2006;43(2):357-63.

17. Zannetti M, Gennaro R, Romeo D. Cathelicidins; a novel protein family with a common proregins and a variable C-terminal antimicrobial domain. FEBS Lett. 1995;374(1):1-5. 18. Skerlavaj B, Benincasa M, Risso A, Zanetti M, Gennaro R. SMAP29: a potent antibacterial and antifungal peptide from sheep leukocytes. FEBS Lett. 1999;463(1-2):58-62.

19. Larrick JW, Lee J, Ma S, Li X, Francke U, Wright SC, et al. Structural, functional analysis and localization of the human CAP18 gene. FEBS Lett. 1996;398(1):74-80.

20. Travis SM, Anderson NN, Forsyth WR, Espiritu C, Conway BD, Greenberg EP, et al. Bactericidal activity of mammalian cathelicidinderived peptides. Infect Immun. 2000;68(5):2748-2755.
21. Zarember KA, Katz SS, Tack BF, Doukhan L, Weiss J, Elsbach P. Host defense functions of proteolytically processed and parent (unprocessed) cathelicidins of rabbit granulocytes. Infect Immun. 2002;70(2):569-76.

22. Lohrasbi-Nejad A, Torkzadeh-Mahani M, Hosseinkhani S. Heterologous expression of a hydrophobin HFB1 and evaluation of its contribution to producing stable foam. Protein Expr Purif. 2016;118:25-30.

23. Choyam S, Lokesh D, Bheemakere Kempaiah B, Kammara R. Assessing the antimicrobial activities of Ocins. Front Microbiol. 2015;6:1034. 24. Hong IP, Lee SJ, Kim YS, Choi SG. Recombinant expression of human cathelicidin (hCAP18/LL-37) in Pichia pastoris. Biotechnol Lett. 2007;29(1):73-78.

25. Kim SJ, Quan R, Lee SJ, Lee HK, Choi JK. Antibacterial activity of recombinant hCAP18/LL37 protein secreted from Pichia pastoris. J Microbiol. 2009;47(3):358-62.

26. Zhao P, Cao G. Production of bioactive sheep beta-defensin-1 in Pichia pastoris. J Ind Microbiol Biotechnol. 2012;39(1):11-17.

27. Tang XS, Tang ZR, Wang SP, Feng ZM, Zhou D, Li TJ. Expression, purification, and antibacterial activity of bovine lactoferrampinlactoferricin in Pichia pastoris. Appl Biochem Biotech. 2012;166:640-51.

28. Guo C, Huang Y, Zheng H, Tang L, He J, Xiang L. Secretion and activity of antimicrobial peptide cecropin D expressed in Pichia pastoris. Exp Ther Med. 2012;4(6):1063-1068.

29. Burrowers OJ, Diamond G, Lee TC. Recombinant expression of Pleurocidin cDNAusing the Pichia pastoris expression system. J Biomed Biotechnol. 2005;2005(4):374-384.

30. Li L, Wang JX, Zhao XF, Kang CJ, Liu N, Xiang $\mathrm{JH}$, et al. High level expression, purification, and characterization of the shrimp antimicrobial peptide, Ch-penaeidin, in Pichia pastoris. Protein Exp Purif. 2005;39(2):144-51.

31. Ellis SB, Brust PF, Koutz PJ, Waters AF, Harpold MM, Gingeras TR. Isolation of alcohol oxidase and two other methanol regulatable genes from the yeast Pichia pastoris. Mol Cell Biol. 1985;5(5):1111-21.

32. Waterham HR, Digan ME, Koutz PJ, Lair SV, Cregg JM. Isolation of the Pichia pastoris 
glyceraldehyde-3-phosphate dehydrogenase gene and regulation and use of its promoter. Gene. 1997;186(1):37-44.

33. Chen H, Xu Z, Peng L, Fang X, Yin X, Xu N, et al. Recent advances in the research and development of human defensins. Peptides. 2006;27(4):931-40.

34. Ebbensgaard A, Mordhorst H, Overgaard MT, Nielsen CG, Aarestrup FM, Hansen EB.
Comparative Evaluation of the Antimicrobial Activity of Different Antimicrobial Peptides against a Range of Pathogenic Bacteria. PLoS ONE. 2015;10:e0144611.

35. Larrick JW, Hirata M, Shimomoura Y, Yoshida $\mathrm{M}$, Zheng $\mathrm{H}$, Zhong $\mathrm{J}$, et al. Antimicrobial Activity of Rabbit CAP18-Derived Peptides. Antimicrob Agents Chemother. 1993;37(12):2534-9. 